\title{
Evaluation of an anti-stigma campaign related to common mental disorders in rural India: a mixed methods approach
}

\author{
P. K. Maulik ${ }^{1,2 *}$, S. Devarapalli ${ }^{1}$, S. Kallakuri ${ }^{1}$, A. Tewari ${ }^{1}$, S. Chilappagari ${ }^{1}$, M. Koschorke ${ }^{3}$ and \\ G. Thornicroft ${ }^{3}$ \\ ${ }^{1}$ Research \& Development, George Institute for Global Health, New Delhi, India \\ ${ }^{2}$ George Institute for Global Health, University of Oxford, Oxford, UK \\ ${ }^{3}$ Centre for Global Mental Health, Institute of Psychiatry, Psychology and Neuroscience, King's College, London, UK
}

Background. Stigma related to mental health is a major barrier to help-seeking resulting in a large treatment gap in lowand middle-income countries (LMIC). This study assessed changes in knowledge, attitude and behaviour, and stigma related to help-seeking among participants exposed to an anti-stigma campaign.

Method. The campaign, using multi-media interventions, was part of the SMART Mental Health Project, conducted for 3 months, across 42 villages in rural Andhra Pradesh, in South India. Mixed-methods evaluation was conducted in two villages using a pre-post design.

Results. A total of 1576 and 2100 participants were interviewed, at pre- and post-intervention phases of the campaign. Knowledge was not increased. Attitudes and behaviours improved significantly $(p<0.01)$. Stigma related to help-seeking reduced significantly $(p<0.05)$. Social contact and drama were the most beneficial interventions identified during qualitative interviews.

Conclusion. The results showed that the campaign was beneficial and led to improvement of attitude and behaviours related to mental health and reduction in stigma related to help-seeking. Social contact was the most effective intervention. The study had implications for future research in LMIC.

Received 24 May 2016; Revised 19 September 2016; Accepted 6 October 2016; First published online 2 November 2016

Key words: Common mental disorders, community-based, India, low- and middle-income countries, mental health awareness, stigma.

\section{Introduction}

Stigma is an attribute, behaviour, or reputation which is socially discrediting in a particular way: it causes an individual to be mentally classified by others in an undesirable, rejected stereotype rather than in an accepted, normal one (Goffman, 1963). Stigma has also been conceptualized as a problem with three elements: knowledge (ignorance/misinformation); a problem of attitudes (prejudice); and a problem of behaviour (discrimination) (Thornicroft et al. 2007). Corrigan et al. (2012) outlined three strategies for addressing stigma that can be understood from the theoretical perspectives of knowledge, attitude and behaviour - educational materials that target inaccurate knowledge and stereotypes and try to change them; interpersonal contact

\footnotetext{
* Address for correspondence: Dr P. K. Maulik George Institute for Global Health India, 219-221 Splendor Forum, Jasola, New Delhi 110025, India.

(Email: pmaulik@georgeinstitute.org.in)
}

with members of a stigmatized community that helps to reduce prejudice and change behaviour; and public protests against those who stigmatize other groups such that there is a behaviour change. Two reviews (Corrigan et al. 2012; Thornicroft et al. 2016) have shown that interpersonal contact and to a lesser degree educational materials are intervention strategies that have been effective to some degree.

Stigma related to mental illness is a widespread issue in the world (WHO, 2001), and is a major impediment towards help-seeking for mental disorders (Clement et al. 2015). Especially in low- and middleincome countries (LMIC), lack of awareness about mental health, especially common mental disorders (CMD) such as depression, anxiety, suicidal risk and emotional stress, and stigma against using mental health services are major barriers against help-seeking. This is reflected in estimates that only $15-25 \%$ people suffering from mental disorders receive any kind of treatment in LMIC (WHO World Mental Health Survey Consortium, 2004). In spite of that, little data

This is an Open Access article, distributed under the terms of the Creative Commons Attribution licence (http://creative commons.org/licenses/by/4.0/), which permits unrestricted re-use, distribution, and reproduction in any medium, provided the original work is properly cited. 
exist about suitable interventions in LMIC that address stigma (Semrau et al. 2015).

This paper reports the mixed-methods evaluation of an anti-stigma campaign based on the principles outlined by earlier research (Corrigan et al. 2012; Thornicroft et al. 2016), conducted in rural India that focused on increasing mental health knowledge and awareness. The main objective was to identify any changes in mental health knowledge, attitude and behaviour and stigma related to help-seeking between pre- and post-intervention This campaign was part of a larger study designated SMART (Systematic Medical Appraisal, Referral and Treatment) Mental Health, involving task shifting, and using innovative mobilebased strategies for mental health services delivery for managing CMD, by primary-care health workers in rural India (Maulik et al. 2015).

\section{Method}

\section{Study site}

SMART Mental Health was conducted in West Godavari district in the south Indian state of Andhra Pradesh. The anti-stigma campaign was implemented across 42 villages (30 of which belonged to Scheduled Tribe (ST) area and was supported by a small grant, and 12 to non-Scheduled Tribe areas supported by a larger grant). Both these sets of villages were from the same district and the villagers spoke Telugu. The health systems are similar, though services are scarcer in ST areas. The ST villages are more remote (http://aptribes.gov.in/statistics.htm), smaller in size, and have poorer health indicators (Ministry of Tribal affairs, 2014). It was predetermined at the protocol development stage that the formal evaluation would be conducted in only two villages out of the 12 villages in the non-ST areas. The study in the non-ST villages had been supported for a longer period of time and had a larger budget. Both of these factors provided an opportunity to formally evaluate the anti-stigma campaign in that area.

The two villages (eligible adult population of 2764) were selected purposively and the criteria used for selection were: distance of each village $<40 \mathrm{~km}$ from the field office; eligible population in each village is of average size ( 1500); each village has at least two village health workers (Accredited Social Health Activists; ASHAs); and each village is under a different primary health centre.

\section{Study population}

Evaluation was made on all eligible adults aged $\geqslant 18$ years who provided consent and were available for interview. Those who were too sick or were not able to comprehend the questions due to severe physical or mental illness were excluded.

\section{Study design}

The evaluation of the anti-stigma campaign involved a pre-post study design, using a mixed-methods approach. No control group was present. Pre-intervention data were collected in March 2015. The intervention (the anti-stigma campaign) was delivered over a 3-month period from the middle of March until the end of June 2015. The post-intervention data including qualitative data were collected after the end of the intervention in June-July 2015. While all post-intervention quantitative data were collected then, data on the Barriers to Access to Care Evaluation (BACE; Institute of Psychiatry, King's College London, 2011) were recollected for the whole population in October as there was an error in the programming of the software which resulted in the questionnaire being skipped for many individuals.

Data are reported as per STROBE (Strengthening the Reporting of Observational Studies in Epidemiology) guidelines for reporting observational studies (von Elm et al. 2007).

\section{Development of the intervention}

Prior interventions used in stigma research or programmes for mental health and other health conditions such as HIV were identified, with a focus on India or other LMIC. Discussions with experts in the field (G. T. and M.K.) helped identify key strategies and programmes relevant to our study. The strategies identified were:

(1) Developing printed information, education and communication (IEC) materials. This strategy involved developing brochures, pamphlets and posters on signs and symptoms of CMD such as depression, suicidal risk, stress and how they differed from severe mental disorders; the need for seeking treatment and how it could impact health; issues of stigma related to mental health prevalent in the community. Vignettes on CMD were included in the brochures as examples and discussed. The information from earlier research was adapted to local needs by conducting formative research (Maulik et al. 2016), and the documents were translated into Telugu. CMD were described and the community understood depression/stress/anxiety and suicidal risk. Local terms to describe stress were incorporated in the materials. The brochures and pamphlets were used in the door-to-door campaign and community meetings to raise mental health awareness and discuss issues related to 
stigma. This was repeated 3-4 times with each household in the villages during the intervention phase. The posters and pamphlets were shared with local government offices, schools, and primary health centres and were displayed on their walls or notice boards. This strategy addressed misinformation (lack of knowledge) and used education-based strategies to address that issue.

(2) Involving a person with CMD to talk about his experience. We identified one person and his caregiver who were willing to have a video made of their experience for sharing with others. This video was screened and discussed during the campaign. This used a social contact strategy to raise awareness and reduce stigma.

(3) Developing a promotional video on mental health, stigma and the SMART Mental Health project. A local film actor promoted the video and spoke about CMD, and this was screened during the campaign. This used an education strategy to raise awareness.

(4) Staging a drama by a local theatre group. A theatre group was identified who already had a script on domestic violence, depression and the need for getting treated. The script was modified to complement the information in the IEC materials. Live performances of the drama were organized in eight villages, including the two where the evaluation was conducted. Additionally, video recordings of it were shown to those who missed the live performances, or in other villages where the live performance was not possible. Short clippings were also shown during the door-to-door campaigns. This used an education-based strategy to increase knowledge and attitudes related to CMD.

\section{Mixed-methods evaluation}

Quantitative data were collected at the pre- and postintervention phases. This was conducted by trained field interviewers using a tablet. The interviewers made it clear at the start of the interview that the intervention and the assessments were all related to CMD. Besides questions on socio-demographic status and health-related topics, the key instruments that were used for measuring stigma and mental health awareness were:

- Barriers to Access to Care Evaluation: Treatment Stigma Subscale (BACE-TS version 3) (Institute of Psychiatry, King's College London, 2011). This is a 12-item questionnaire with a 4-point Likert scale asking questions relevant to stigma associated with seeking care for mental illnesses. BACE has been found to have moderate to good reliability and good construct validity (Clement $e t$ al. 2012). The questionnaire was translated into Telugu and back-translated, but no differences were identified. Test-retest reliability, assessed using a standardized Cronbach's alpha test, was 0.85 indicating good internal consistency.

- Mental Health Knowledge, Attitude and Behaviour (KAB; Lund et al. 2012). This is a 16-item questionnaire developed for the PRIME study (Lund et al. 2012) and is based on a number of other tools. It uses a 5-point Likert scale that ascertains mental health knowledge, attitude and behaviours as per the framework for understanding stigma suggested by others (Thornicroft et al. 2007). This was translated into Telugu, and back-translated into English. The subgroups were identified based on discussion with experts and were not based on any psychometric analyses, hence did not have the properties of a scale.

Qualitative data were collected from community members, ASHAs, village leaders and field interviewers, using focus group discussions (FGDs) and in-depth interviews (IDIs). They were conducted after the intervention using a set of open-ended questions that explored their views about stigma against mental health and help-seeking for mental disorders. They were also asked to provide their perceptions on positive/negative attributes of each strategy used in the campaign. Opinions were also sought about marrying/living/working with people with CMD; knowledge about CMD and the need to seek treatment; and societal prejudices. The interviews were conducted in the local language (Telugu) and was audio-recorded. Qualitative data were collected by trained researchers. The recordings were transcribed and translated to English.

\section{Data management and analysis}

Quantitative data were stored in a secure server based at the George Institute India. A statistical plan was developed prior to analysing the data, and drew on analyses done in earlier research (Clement et al. 2012). Response frequency and mean scores were derived wherever applicable for the socio-demographic variables and individual questions of the two questionnaires. The difference in mean score for the $\mathrm{KAB}$ items were calculated. The mean scores for each item on the BACE; proportion of respondents identifying each item as a possible barrier ('a little' or more); proportion of respondents identifying each item as a major barrier ('a lot'); and the rank of each item as a barrier based on the proportion who identified it as a major barrier have been estimated. The mean scores and rank of different items between the pre- and post-evaluation phases were compared using paired $t$ 
tests and McNemar's $\chi^{2}$ test using SAS v. 9.04 (SAS, 2016). These were performed only for subjects for whom information was available at both time-points pre- and post-intervention stages, hence there were fewer observations compared to the total number of observations at each stage.

Qualitative analyses was based on grounded theory and used a thematic framework approach to identify common emerging themes. First, each audiotaped, IDI/FGD was transcribed verbatim, and the textual data files were imported into Nvivo 9 (NVivo, 2010). The researchers (A.T., S.K., S.D.) initially familiarized themselves with the data and during that process identified broad thematic areas. A coding scheme was formulated using an inductive approach. All transcripts were reviewed to identify recurrent themes across individuals and groups, which were then refined into codes. Two researchers (S.K. and A.T.), working together, defined each code category and then individually proceeded to code the text of the interviews. Discrepancies in coding were identified, and consensus was obtained through discussion and clarification of coding categories. Results obtained from the quantitative and qualitative research were collated, using a concurrent triangulation of data from both methods to derive a comprehensive understanding of the antistigma campaign (Hanson et al. 2005).

\section{Ethical standards}

Ethics approval for the study was obtained from the Independent Ethics Committee of the Centre for Chronic Disease Control, New Delhi. Written informed consent was obtained from all participants. The authors assert that all procedures contributing to this work comply with the ethical standards of the relevant national and institutional committees on human experimentation and with the Helsinki Declaration of 1975, as revised in 2008.

\section{Results}

The two villages had a similar sociodemographic profile as the larger set of 12 non-ST villages with respect to mean age ( $\sim 40$ years), gender distribution $(\sim 60 \%$ female), education ( $\sim 30 \%$ with no schooling), marital status ( $\sim 80 \%$ married), occupation ( $\sim 35 \%$ being housewife/retired) (data not shown). Out of 4600 people in the two villages, 2764 (60.1\%) eligible adults were identified. The pre- and post-intervention data were collected from 1576 (57\%) and 2100 (76\%) of the eligible adults, respectively. Due to the presence of local industries which are seasonal, a large proportion of the villagers had left during the pre-intervention phase to work there, but returned later on. While we cannot comment on when they returned and for how long they received the intervention, the pre-post assessment is based on only paired observations who were interviewed at both times. As discussed in the study design the BACE was re-administered, and 1783 out of the 2100 interviewed at post-intervention could be interviewed (Supplementary Table S1).

\section{Quantitative analysis}

The socio-demographic characteristics of the study participants at both pre- and post-intervention phases were similar with more than 55\% being women; about half being employed in unorganized sectors involving farming, contract labour, and small shops; about a third having no formal education; and more than $80 \%$ being 'currently married'. The mean age of the participants was around 42 years at both time-points (Table 1).

Television was the commonest source of information on mental health, and hospitals and clinics were identified as the places to receive treatment for mental disorders. About a third knew of someone with a mental illness. Within the knowledge domain majority felt that people with mental illness 'tend to be violent' and cannot lead a 'rewarding life', but they can be treated especially with medications. The attitude towards people with mental illness was ambivalent in that on one hand the majority felt that people with mental illness 'should not get married' and 'should not be given any responsibility', but on the other the majority felt that people with mental illness are 'far less of a danger than supposed' and that society needed to have a 'tolerant attitude towards people with mental illness'. From a behaviour perspective, the majority were willing to share their life with someone with mental illness either at work, or being in a relationship or having someone with mental illness as neighbours. The majority were willing to share personal mental illness details with family (Supplementary Table S2).

Compared to the pre-intervention data, the postintervention data showed statistically significant improvement of scores (lower scores) on most of the attitude and behaviour domain-related questions except the item 'mentally ill people shouldn't get married', which showed a statistically significant increased score by 0.13 (s.D. $=1.89) \quad(p=0.01)$. No significant knowledge gain was observed. By contrast, there was a statistically significant worse score on the item 'people with mental illness cannot live a good, rewarding life' (Table 2).

The BACE responses indicated a low level of stigma and this reduced even further following the intervention. The major difference observed between pre- and post-intervention was that the proportion of people who had identified each item as even a possible barrier or had identified them as a major barrier, had both 
Table 1. Sociodemographic characteristics of the study participants

\begin{tabular}{lcc}
\hline & $\begin{array}{c}\text { Pre-intervention } \\
(N=1576), n(\%)\end{array}$ & $\begin{array}{c}\text { Post-intervention } \\
(N=2100), n(\%)\end{array}$ \\
Characteristic & & \\
\hline Gender & $929(58.95)$ & $1150(54.76)$ \\
Female & $647(41.05)$ & $950(45.24)$ \\
Male & & \\
Occupation & $612(38.83)$ & $760(36.19)$ \\
House wife/retired & $40(2.54)$ & $59(2.81)$ \\
Organized sector & $785(49.81)$ & $1090(51.90)$ \\
Unorganized sector & $139(8.82)$ & $191(9.10)$ \\
Other & & \\
Education & $49(3.11)$ & $80(3.81)$ \\
Graduate/ & & $422(20.10)$ \\
$\quad$ postgraduate & $267(16.94)$ & $934(44.48)$ \\
High school & $746(47.34)$ & $640(30.48)$ \\
Primary school & $507(32.17)$ & $24(1.14)$ \\
No school & $7(0.44)$ & $1703(81.10)$ \\
Other & & $199(9.48)$ \\
Marital status & $1261(80.01)$ & $198(9.43)$ \\
Currently married & $151(9.58)$ & \\
Never married & $164(10.41)$ & \\
Separated/divorced/ & & \\
$\quad$ widowed & & \\
Age (years) & & \\
Mean (s.D.) & & \\
Range & & \\
\hline
\end{tabular}

$N$, Total number of participants in each phase.

$n$, Number of participants with particular characteristic.

reduced. The only two items which continued to rank among the top three major barriers at both time points were 'concern that my children may be taken into care or that I may lose access or custody without my agreement' and 'concern about what people at work might think, say or do' (Supplementary Table S3-5).

All the items on the BACE showed statistically significant lower scores at post-intervention compared to pre-intervention and this was true for the total mean BACE score also (Table 3).

Table 4 shows that for each question on the BACE, the proportion of participants who found that each barrier was a major issue ('a lot') had reduced significantly between pre- and post-intervention.

\section{Qualitative analyses}

Overall, five FGDs and six IDIs were conducted in two villages:

- Four FGDs were conducted with community members (18 male, 15 female, age 22-65 years), two FGDs in each village segregated by gender.

- One FGD was conducted with field investigators (six male, four female, age 22-34 years).
- Four IDI were conducted with ASHAs (females aged 31-42 years), and two with a village leader from each village (a 54-year-old male and a 48year-old female).

The results from all the FGDs and IDIs are collated and presented under five major themes (Table 5).

\section{Theme I. Awareness about the anti-stigma campaign} activities

The majority of the participants were aware of the campaign activities, such as door-to-door campaign, drama and the video films, but few were aware about the posters and pamphlets exhibited in public places and primary health centres. All stakeholders felt that such interactive campaigns should be organized regularly.

\section{Theme II. Effective strategies used to create awareness}

Overall, most of the community members felt that they gained knowledge about CMD and related issues through the campaign. Most participants opined that the drama and the film of the person discussing his personal mental illness were the most effective strategies because they showed how people with mental illness suffer, and how it leads to depression. Some of the participants could also relate to the characters shown in the drama. Many participants mentioned that the drama and videos made them realize that they should not desert or abuse persons suffering from psychological problem, rather provide support to them.

\section{Theme III. Changes in knowledge about CMD and stigma}

During the discussions most of the participants cited different reasons for the cause of mental disorder. However, they indicated that the new knowledge resulted in a change in their perceptions about mental disorders and attitude towards people with mental disorders, e.g. they felt that marriage with someone having mental illness is not an issue for them anymore.

The village leaders agreed that increase in mental disorders was a cause of concern for them and they supported this campaign. They felt that the campaign was able to dispel some myths regarding mental illness.

Community members added that they felt confident approaching a person and persuading him/her or family members to seek treatment from a doctor.

\section{Theme IV. Access to treatment}

Some of the community members shared that they were not aware about existing treatment facilities before the implementation of this programme. They were concerned about the non-availability of treatment 
Table 2. Change in Knowledge, Attitude and Behaviour scores between pre-and post-intervention

\begin{tabular}{|c|c|c|c|c|c|}
\hline Domain & Question & $\begin{array}{l}\text { Pre-intervention } \\
\text { mean (s.D.) }\end{array}$ & $\begin{array}{l}\text { Post-intervention } \\
\text { mean (s.D.) }\end{array}$ & $\begin{array}{l}\text { Difference in } \\
\text { mean (s.D.), } n\end{array}$ & $p$ value \\
\hline \multirow[t]{4}{*}{ Knowledge } & Mentally ill people tend to be violent & $2.2(1.21)$ & $2.2(1.27)$ & $-0.01(1.76), 1183$ & 0.8428 \\
\hline & $\begin{array}{l}\text { People with mental illness cannot live a } \\
\text { good, rewarding life }\end{array}$ & $2.1(1.05)$ & $1.7(1.00)$ & $-0.30(1.48), 1238$ & $<0.0001$ \\
\hline & $\begin{array}{l}\text { People with severe mental health problems } \\
\text { can fully recover }\end{array}$ & $1.7(0.92)$ & $1.7(0.96)$ & -0.05 (1.29), 1352 & 0.1226 \\
\hline & $\begin{array}{l}\text { Medication can be an effective treatment for } \\
\text { people with mental health problems }\end{array}$ & $1.6(0.89)$ & $1.5(0.88)$ & $-0.03(1.22), 1396$ & 0.2927 \\
\hline \multirow[t]{4}{*}{ Attitude } & Mentally ill people shouldn't get married & $2.3(1.31)$ & $2.4(1.43)$ & 0.13 (1.89), 1252 & 0.0137 \\
\hline & $\begin{array}{l}\text { People with mental health problems are far } \\
\text { less of a danger than most people suppose }\end{array}$ & $2.0(1.01)$ & $1.6(0.85)$ & -0.34 (1.29), 1269 & $<0.0001$ \\
\hline & $\begin{array}{l}\text { We need to adopt a far more tolerant } \\
\text { attitude toward people with mental illness } \\
\text { in our society }\end{array}$ & $1.5(0.80)$ & $1.2(0.56)$ & $-0.23(0.99), 1435$ & $<0.0001$ \\
\hline & $\begin{array}{l}\text { People with mental health problems should } \\
\text { not be given any responsibility }\end{array}$ & $2.2(1.23)$ & $1.9(1.20)$ & $-0.31(1.68), 1335$ & $<0.0001$ \\
\hline \multirow[t]{5}{*}{ Behaviour } & $\begin{array}{l}\text { If you suffered from a mental health } \\
\text { problem would you tell your family or } \\
\text { friends }^{\text {a }}\end{array}$ & $2.4(0.88)$ & $2.8(0.49)$ & $0.42(0.98), 1575$ & $<0.0001$ \\
\hline & $\begin{array}{l}\text { I would be willing to live with someone } \\
\text { with a mental health problem }\end{array}$ & $1.9(1.07)$ & $1.6(1.03)$ & $-0.27(1.44), 1406$ & $<0.0001$ \\
\hline & $\begin{array}{l}\text { I would be willing to work with someone } \\
\text { with a mental health problem }\end{array}$ & $1.9(1.11)$ & $1.6(1.01)$ & $-0.29(1.39), 1404$ & $<0.0001$ \\
\hline & $\begin{array}{l}\text { I would be willing to live nearby someone } \\
\text { with a mental health problem }\end{array}$ & $1.9(1.10)$ & $1.6(0.98)$ & $-0.31(1.41), 1393$ & $<0.0001$ \\
\hline & $\begin{array}{l}\text { I would be willing to continue a } \\
\text { relationship with a friend who developed } \\
\text { a mental health problem }\end{array}$ & $1.8(1.01)$ & $1.5(0.90)$ & $-0.26(1.28), 1412$ & $<0.0001$ \\
\hline
\end{tabular}

$p$ value is calculated using paired $t$ test; $n$, participants who responded to each item at both times.

${ }^{\text {a }}$ Coded differently - no one $=1$, friend $=2$, family $=3$ (higher scores indicating bias towards family).

facilities in their villages and that they had to travel far to receive treatment.

\section{Theme V. Suggested strategies}

Almost all the participants wanted more plays and films on people with mental disorders for creating awareness about mental health issues. Some of the participants suggested organizing camps in their villages where they could interact with experts, or a doctor to clarify doubts. Some of the field investigators and ASHAs suggested using media to create awareness. The field investigators suggested involving school teachers such that mental health awareness can be imparted to school children.

\section{Discussion}

This study used a mixed-methods approach to evaluate an anti-stigma campaign related to CMD using a prepost design. To the best of our knowledge this is the first study from a LMIC that reports the results of such a campaign on a large community-based population. The results suggest that the knowledge of the study participants about mental health did not differ significantly following the intervention, but both their attitudes and behaviours did change for the better in most situations. This is one of the few studies globally, which measured changes in behaviour using a set of questions around hypothetical scenarios, although not in real-life situations. Stigma towards accessing mental healthcare was also reduced following the intervention.

The study design is limited by being a pre-post method, hence efficacy of the intervention could not be ascertained as in a randomized controlled study. Moreover, since it does not have a control group, the results need to be interpreted with caution. The KAB and BACE have not undergone stringent psychometric assessment within the specific study population, but nonetheless, both tools have undergone translation and back-translation and the test-retest reliability of the BACE was found to be good. Although the 
Table 3. Change in mean scores for each barrier in the Barriers to Access to Care Evaluation (BACE) - Treatment Stigma Subscale

\begin{tabular}{|c|c|c|c|c|}
\hline Question & $\begin{array}{l}\text { Pre-intervention } \\
\text { Mean (s.D.) }\end{array}$ & $\begin{array}{l}\text { Post-intervention } \\
\text { Mean (s.D.) }\end{array}$ & $\begin{array}{l}\text { Difference of } \\
\text { mean (S.D.), } n\end{array}$ & $p$ value \\
\hline $\begin{array}{l}\text { Concern that I might be seen as weak for having a mental } \\
\text { health problem }\end{array}$ & $0.4(0.67)$ & $0.1(0.39)$ & $-0.23(0.772), 1348$ & $<0.0001$ \\
\hline $\begin{array}{l}\text { Concern that it might harm my chances when applying for } \\
\text { jobs }\end{array}$ & $0.6(0.81)$ & $0.1(0.34)$ & $-0.36(0.827), 160$ & $<0.0001$ \\
\hline Concern about what my family might think, say, do or feel & $0.4(0.67)$ & $0.2(0.45)$ & $-0.24(0.808), 1348$ & $<0.0001$ \\
\hline Feeing embarrassed or ashamed & $0.4(0.66)$ & $0.2(0.40)$ & $-0.18(0.759), 1348$ & $<0.0001$ \\
\hline Concern that I might be seen as crazy & $0.4(0.69)$ & $0.1(0.37)$ & $-0.24(0.775), 1348$ & $<0.0001$ \\
\hline Concern that I might be seen as a bad parent & $0.4(0.67)$ & $0.2(0.38)$ & $-0.23(0.756), 1250$ & $<0.0001$ \\
\hline Concern that people I know might find out & $0.4(0.67)$ & $0.1(0.35)$ & $-0.26(0.708), 1348$ & $<0.0001$ \\
\hline $\begin{array}{l}\text { Concern that people might not take me seriously if they } \\
\text { found out I was having professional care }\end{array}$ & $0.4(0.66)$ & $0.1(0.43)$ & $-0.28(0.763), 1348$ & $<0.0001$ \\
\hline $\begin{array}{l}\text { Not wanting a mental health problem to be on my medical } \\
\text { records }\end{array}$ & $0.3(0.75)$ & $0.1(0.23)$ & $-0.28(0.791), 1348$ & $<0.0001$ \\
\hline $\begin{array}{l}\text { Concern that my children may be taken into care or that I } \\
\text { may lose access or custody without my agreement }\end{array}$ & $0.4(0.73)$ & $0.2(0.40)$ & $-0.22(0.842), 1244$ & $<0.0001$ \\
\hline Concern about what my friends might think, say or do & $0.4(0.70)$ & $0.1(0.37)$ & $-0.30(0.784), 1348$ & $<0.0001$ \\
\hline Concern about what people at work might think, say or do & $0.5(0.73)$ & $0.2(0.52)$ & $-0.24(0.883), 1348$ & $<0.0001$ \\
\hline Overall mean & $0.4(0.08)$ & $0.1(0.04)$ & $0.3(0.09)$ & $<0.0001$ \\
\hline
\end{tabular}

$n$, Number of participants at both pre- and post-intervention.

$p$ value is calculated using paired $t$ test.

Table 4. Change in proportion between pre- and post-intervention on Barriers to Access to Care Evaluation (BACE) - Treatment Stigma Subscale who found barriers affecting them 'a lot'

\begin{tabular}{|c|c|c|c|c|}
\hline Question & $n$ & $\begin{array}{l}\% \text { Reporting as } \\
\text { major barrier (a lot) } \\
\text { pre-intervention }\end{array}$ & $\begin{array}{l}\% \text { Reporting as } \\
\text { major barrier (a lot) } \\
\text { post-intervention }\end{array}$ & $p$ value \\
\hline $\begin{array}{l}\text { Concern that I might be seen as weak for having a mental health } \\
\text { problem }\end{array}$ & 1348 & 1.78 & 0.14 & $<0.0001$ \\
\hline Concern that it might harm my chances when applying for jobs & 160 & 0.63 & 0.05 & 0.0196 \\
\hline Concern about what my family might think, say, do or feel & 1348 & 1.52 & 0.05 & $<0.0001$ \\
\hline Feeing embarrassed or ashamed & 1348 & 1.52 & 0.05 & $<0.0001$ \\
\hline Concern that I might be seen as crazy & 1348 & 1.46 & 0.14 & 0.0003 \\
\hline Concern that I might be seen as a bad parent & 1250 & 1.27 & 0.05 & 0.0013 \\
\hline Concern that people I know might find out & 1348 & 1.33 & 0.05 & 0.0008 \\
\hline $\begin{array}{l}\text { Concern that people might not take me seriously if they found out } \\
\text { I was having professional care }\end{array}$ & 1348 & 1.21 & 0.05 & 0.0008 \\
\hline Not wanting a mental health problem to be on my medical records & 1348 & 4.70 & 0.05 & $<0.0001$ \\
\hline $\begin{array}{l}\text { Concern that my children may be taken into care or that I may lose } \\
\text { access or custody without my agreement }\end{array}$ & 1244 & 3.17 & 0.10 & $<0.0001$ \\
\hline Concern about what my friends might think, say or do & 1348 & 1.65 & 0.05 & $<0.0001$ \\
\hline Concern about what people at work might think, say or do & 1348 & 2.16 & 0.67 & 0.0112 \\
\hline
\end{tabular}

$p$ value is calculated using McNemar's $\chi^{2}$ test.

strategies used are generalizable to similar rural settings, the content and language may not be generalizable to other populations. All eligible adults in the villages were recruited, and the profile of the preand post-intervention population were similar, hence recruitment bias is negligible, even though this was not a random sample. The responses to the BACE at post-intervention were collected later and it may have resulted in attenuated effect. However, given the magnitude of change in BACE scores and the 
Table 5. Summary of qualitative research

\begin{tabular}{|c|c|c|c|c|}
\hline $\begin{array}{l}\text { Anti-stigma } \\
\text { campaign strategies }\end{array}$ & Purpose & Themes & Findings & Examples of verbatim quotes \\
\hline \multirow{4}{*}{$\begin{array}{l}\text { - IEC Material - } \\
\text { brochure, } \\
\text { pamphlets and } \\
\text { posters } \\
\text { - Video film of a } \\
\text { person with } \\
\text { mental disorder } \\
\text { - Street play on } \\
\text { domestic violence } \\
\text { and mental } \\
\text { disorder }\end{array}$} & \multirow{4}{*}{$\begin{array}{l}\text { Explore knowledge about the process of } \\
\text { delivering the anti-stigma campaign - } \\
\text { appropriateness and usefulness of the } \\
\text { campaign; relevance to local culture and } \\
\text { settings } \\
\text { - Assess the impact of anti-stigma campaign } \\
\text { on the community environment }\end{array}$} & $\begin{array}{l}\text { Awareness about the } \\
\text { anti-stigma } \\
\text { campaign activities }\end{array}$ & $\begin{array}{l}\text { Majority were aware of door-to- } \\
\text { door campaign, drama and the } \\
\text { video films }\end{array}$ & $\begin{array}{l}\text { - 'Programme was useful'...'We understood that } \\
\text { how people with psychological problem suffer } \\
\text { and how it leads to depression' (51-year-old } \\
\text { female community member) }\end{array}$ \\
\hline & & $\begin{array}{l}\text { Effective strategies } \\
\text { used to create } \\
\text { awareness }\end{array}$ & $\begin{array}{l}\text { - Street play and video film were } \\
\text { favourite medium in } \\
\text { dissemination of information } \\
\text { related to mental disorder }\end{array}$ & $\begin{array}{l}\text { - An adult leader shared, 'Out of all, how a girl } \\
\text { suffers and how to [one] looks after that girl, } \\
\text { and the whole characterization of that girl was } \\
\text { very nice. The character initiated us to think } \\
\text { about something' (54-year-old male village } \\
\text { leader) } \\
\text { - '... we came to know about [Kiran] who was in } \\
\text { hospital suffering from mental disorder and } \\
\text { was cured by taking treatment' (45-year-old } \\
\text { female community member) }\end{array}$ \\
\hline & & $\begin{array}{l}\text { Changes in } \\
\text { knowledge about } \\
\text { common mental } \\
\text { disorders and stigma }\end{array}$ & $\begin{array}{l}\text { - Gained knowledge about } \\
\text { mental disorder and related } \\
\text { issues } \\
\text { - Increase in awareness on } \\
\text { existing treatment facilities }\end{array}$ & $\begin{array}{l}\text { - A leader mentioned: 'Earlier we thought that } \\
\text { mental illness can't be cured. Now we tell our } \\
\text { family members and others that we should } \\
\text { support the person facing such problem and } \\
\text { take him/her to the doctor' (48-year-old female } \\
\text { village leader). } \\
\text { - '... I hope that it may [be] cure[d] ...' while } \\
\text { being married (Group's view) }\end{array}$ \\
\hline & & Access to treatment & $\begin{array}{l}\text { - Less accessibility to healthcare } \\
\text { facility for mental health } \\
\text { treatment in the same village }\end{array}$ & $\begin{array}{l}\text { - 'We are taking medicine and treatment for this } \\
\text { [mental illness] in other city, which is very far' } \\
\text { (52-year-old male community member) }\end{array}$ \\
\hline
\end{tabular}


sample size, a less attenuated result would only increase the difference in scores and not have any significant impact on the implications.

\section{Changes in outcomes related to knowledge, attitude and behaviour, and help-seeking}

It was understandable that most people received information about mental health via films and television shows, as these are the commonest media they are exposed to. Most participants identified hospitals and clinics as the primary areas for receiving care for mental illness, as generally people are mainly aware about severe mental disorders for which care was sought in hospitals and clinics. CMD were neither known as mental health conditions nor was treatment sought. However, about $5 \%$ of the participants preferred religious leaders/traditional healers, and earlier research has identified using similar services, too, in India (Hashimoto et al. 2015).

Comparing pre-post data on knowledge, attitude and behaviour, it was evident that significant changes were observed for attitude and behavioural components, with little impact on increase in knowledge. This has also been reported in a recent review which found similar results when exploring evidence-based interventions for reducing stigma and discrimination in mental health (Thornicroft et al. 2016). The results also indicate that at post-intervention more people agreed with the comment that 'people with mental illness cannot lead a good rewarding life'. This contrasts with the other more positive views observed following the intervention. One reason for this could be that this particular question was interpreted in light of the quality of life. So while people felt that treatment helps and the mental health condition can improve, they were not sure of the overall impact on the quality of life and productivity. This needs further research. Mental health attitudes has been found to improve following anti-stigma and mental health awareness campaigns, but not knowledge, even in high-income countries, and no conclusive data are available for behaviour change. Data from LMIC are almost negligible and what little exists is inconclusive about the effectiveness of the interventions or the overall outcomes (Semrau et al. 2015).

Although in our study, the quantitative data failed to show significant knowledge gain at post intervention, qualitative data suggests changes in knowledge both among the community and key stakeholders, such as village leaders. However, while the quantitative assessment showed a small but statistically significant increase in people endorsing the statement that 'people with mental illness shouldn't get married', the qualitative data suggested that people's views varied. The reason for this is that while the overall attitude is that people with mental illness should not marry as that was thought to affect the spouses' life, in the FGDs they opined that they did not see any harm in marrying someone with mental illness as it probably would get cured. This change in attitude could be because they had additional information about benefits of treatment for CMD through the anti-stigma campaign. Prior to the qualitative interviews the context of the campaign were re-emphasized and this may have helped them understand the point better.

Overall, stigma against help-seeking was low and reflects trends obtained from other research from LMIC (Semrau et al. 2015). A third of the population had a neighbour or family member with mental illness and that may have acted as an interpersonal contact resulting in reduced stigma. Little prior experience with mental health services may have also contributed to low scores on the BACE due to poor understanding of the stigma associated with seeking treatment. The anti-stigma campaign reduced stigma even further. Two concerns that continued to be ranked highly at post-intervention were concerns that the children may be taken away without agreement and what colleagues at the workplace may think of a person seeking mental health treatment - barriers identified in an earlier review of both quantitative and qualitative studies (Thornicroft, 2008; Clement et al. 2015). Both these issues have policy implications for confidentiality of personal health records at the workplace and policies around childcare and social support for parents with mental illness.

\section{Intervention strategies}

This anti-stigma campaign used a number of intervention strategies and it is not possible to delineate which particular strategy was most effective. However, social contact, even if indirect in the form of a video showing a person with mental illness talking about his experiences, and the drama were clearly identified as the most effective strategies in the qualitative analyses. Social contact has been identified as an effective strategy in earlier research too (Corrigan et al. 2012; Thornicroft et al. 2016). Overall, the community found the anti-stigma campaign beneficial and wanted teachers and doctors to be involved too. They suggested using multi-media approaches, and organizing the campaigns via smaller camps. While in our study, no one commented about the benefits of the education material, it was apparent during the discussions that they had gained some information about treatment options and stigma from the mental health awareness materials shared with them. Mental health 
education has been found to be effective, especially in interventions conducted for more than 4 weeks (Thornicroft et al. 2016).

\section{Implications for future programmes and research}

Addressing mental health stigma is essential to reduce treatment gap, as it helps to increase help-seeking. Developing strategies to reduce stigma and promote mental health are identified as key strategies in the World Health Organization's Mental Health Action Plan for 2013-2020 (WHO, 2013), and more randomized controlled trials are needed in Indian populations to generate evidence. Future research needs to explore newer techniques of sharing information related to stigma and discrimination, and develop strategies for specific populations such as women, students, and caregivers, as studies indicate that there are differences in the effectiveness of different strategies among population subgroups (Corrigan et al. 2012; Thornicroft et al. 2016). Research using mixed methods also needs to explore the level of stigma in the community and see if similar low levels are obtained and ascertain explanations for such. Strategies also need to be more inclusive and involve peer-led participatory models to encourage wider dissemination, especially for specific groups such as adolescents and women, who may have specific issues that lead to stigma and such could be identified and discussed more effectively through peer-led processes (Bulanda et al. 2014).

\section{Supplementary material}

The supplementary material for this article can be found at https://doi.org/10.1017/S0033291716002804

\section{Acknowledgements}

P.K.M. is an Intermediate Career Fellow of the WT/ DBT India Alliance. G.T. is supported by the National Institute for Health Research (NIHR) Collaboration for Leadership in Applied Health Research and Care South London at King's College London Foundation Trust. The views expressed are those of the author(s) and not necessarily those of the NHS, the NIHR or the Department of Health. G.T. acknowledges financial support from the Department of Health via the National Institute for Health Research (NIHR) Biomedical Research Centre and Dementia Unit awarded to South London and Maudsley NHS Foundation Trust in partnership with King's College London and King's College Hospital NHS Foundation Trust. G.T. is supported by the European Union Seventh Framework Programme (FP7/2007-2013) Emerald project. M.K. was supported by a National Institute for Health Research (NIHR) funded Clinical Lectureship.

Vamsi Krishna Vadlamani of George Institute for Global Health India provided additional support for data analysis.

The SMART Mental Health Project is supported by the WT/DBT Fellowship (IA/I/13/1/500879) and a Grand Challenges Canada Grant (No. 0524-01-10) on which P.K.M. is the Principal investigator.

\section{Declaration of Interest}

None.

\section{References}

Bulanda JJ, Bruhn C, Byro-Johnson T, Zentmyer M (2014). Addressing mental health stigma among young adolescents: evaluation of a youth-led approach. Health $\mathcal{E}$ Social Work 39, 73-80.

Clement S, Brohan E, Jeffery D, Henderson C, Hatch SL, Thornicroft G (2012). Development and psychometric properties the Barriers to Access to Care Evaluation scale (BACE) related to people with mental ill health. BMC Psychiatry 12, 36.

Clement S, Schauman O, Graham T, Maggioni F, EvansLacko S, Bezborodovs N, Morgan C, Rüsch N, Brown JS, Thornicroft G (2015). What is the impact of mental healthrelated stigma on help-seeking? A systematic review of quantitative and qualitative studies. Psychological Medicine 45, 11-27.

Corrigan PW, Morris SB, Michaels PJ, Rafacz JD, Rüsch N (2012). Challenging the public stigma of mental illness: a meta-analysis of outcome studies. Psychiatric Services 63, 963-973.

Goffman E (1963). Stigma: Notes on the Management of Spoiled Identity. Prentice-Hall: New York.

Hanson WE, Creswell JW, Clark VLP, Petska KS, Creswell JD (2005). Mixed methods research designs in counseling psychology. Journal of Counseling Psychology 52, 224-235.

Hashimoto N, Fujisawa D, Giasuddin NA, Kenchaiah BK, Narmandakh A, Dugerragchaa K, Tamrakar SM, Adhikari SR, Sartorius N (2015). Pathways to mental health care in Bangladesh, India, Japan, Mongolia, and Nepal. Asia Pacific Journal of Public Health 27, NP1847-57. Institute of Psychiatry, King's College London (2011). Barriers to Access to Care Evaluation - Treatment Stigma Subscale (BACE-TS version 3). Institute of Psychiatry: London.

Lund C, Tomlinson M, De Silva M, Fekadu A, Shidhaye R, Jordans M, Petersen I, Bhana A, Kigozi F, Prince M, Thornicroft G, Hanlon C, Kakuma R, McDaid D, Saxena S, Chisholm D, Raja S, Kippen-Wood S, Honikman S, Fairall L, Patel V (2012). PRIME: a programme to reduce the treatment gap for mental disorders in five low- and middle-income countries. PLoS Medicine 9, e1001359.

Maulik PK, Devarapalli S, Kallakuri S, Praveen D, Jha V, Patel A (2015). Systematic Medical Appraisal, Referral and 
Treatment (SMART) Mental Health Programme for providing innovative mental health care in rural communities in India. Global Mental Health 2, e13.

Maulik PK, Tewari A, Devarapalli S, Kallakuri S, Patel A (2016). The Systematic Medical Appraisal, Referral and Treatment (SMART) Mental Health Project: development and testing of electronic decision support system and formative research to understand perceptions about mental health in rural India. PLoS ONE 11: e0164404.

Ministry of Tribal Affairs, Government of India (2014). Report of the High Level Committee on Socio-economic, Health and Educational Status of Tribal Communities of India. Government of India: New Delhi.

NVivo (2010). NVivo qualitative data analysis Software, Version 9, QSR International Pty Ltd.

SAS (2016) SAS/STAT Version 9.04. SAS Institute Inc., Cary, NC, USA.

Semrau M, Evans-Lacko S, Koschorke M, Ashenafi L, Thornicroft G (2015). Stigma and discrimination related to mental illness in low- and middle-income countries. Epidemiology and Psychiatric Sciences 24, 382-394.

Thornicroft G (2008). Stigma and discrimination limit access to mental health care. Epidemiologia e Psichiatria Sociale 17, 14-19.
Thornicroft G, Mehta N, Clement S, Evans-Lacko S, Doherty M, Rose D, Koschorke M, Shidhaye R, O'Reilly C, Henderson C (2016). Evidence for effective interventions to reduce mental-health-related stigma and discrimination. Lancet 387, 1123-1132.

Thornicroft G, Rose D, Kassam A, Sartorius N (2007). Stigma: ignorance, prejudice or discrimination? British Journal of Psychiatry 190, 192-193.

von Elm E, Altman DG, Egger M, Pocock SJ, Gotzsche PC, Vandenbroucke JP (2007). The Strengthening the Reporting of Observational Studies in Epidemiology (STROBE) Statement: guidelines for reporting observational studies. PLoS Medicine 4, e296.

WHO (2001). The World Health Report 2001-Mental Health: New Understanding, New Hope. World Health Organization: Geneva, Switzerland.

WHO (2013). Mental Health Action Plan 2013-2020. World Health Organization: Geneva, Switzerland. 2013. (http:// apps.who.int/iris/bitstream/10665/89966/1/9789241506021_ eng.pdf?ua=1). Accessed 22 May 2016.

WHO World Mental Health Survey Consortium (2004). Prevalence, Severity, and Unmet Need for Treatment of Mental Disorders in the World Health Organization World Mental Health Surveys. Journal of American Medical Association 291, 2581-2590. 